\title{
Evidence for syntectonic crystallization for the mudstone to slate transition at Lehigh Gap, Pennsylvania, U.S.A.*
}

\author{
Jung Hoo Lee $\dagger \ddagger$, Donald R. Peacor $\dagger$, Daniel D. Lewis $\$ \|$ and Robert P. Wintsch $\S$ \\ † Department of Geological Sciences, University of Michigan, Ann Arbor, MI 48109, U.S. A. \\ $\ddagger$ Present address: Department of Geology, Jeonbuk National University, Jeonju, South Korea. \\ $\S$ Department of Geology, Indiana University, Bloomington, IN 47405, U.S.A \\ Present address: Exxon Company, USA, P.O. Box 120, Denver, CO 80201, U.S.A.
}

(Received 10 August 1984; accepted in revised form 23 October 1985)

\begin{abstract}
Data primarily for phyllosilicates have been obtained for the continuous transitional sequence from mudstone to slate with well-developed slaty cleavage at Lehigh Gap, Pennsylvania, and for slates from quarries in the same area. Samples were studied by optical microscopy, powder X-ray diffraction and electron microprobe analysis, with emphasis on transmission and analytical electron microscopy. Mineral grains are virtually free of deformation-induced strain. Concomitant with the gradual development of cleavage normal to bedding the following changes are observed or confirmed: (1) the orientation of phyllosilicate grains changes discontinuously from being preferentially parallel to bedding to being parallel to cleavage; (2) crystal imperfections as expressed in layer terminations, low angle grain boundary-like features and other defects decrease in density; (3) complex mixed layering is replaced by homogeneous packets of layers of single phases and (4) illite transforms to muscovite, with increase in $\mathrm{K}+\mathrm{Al}$ and change from a $1 \mathrm{M}_{d}$ to $2 \mathrm{M}$ polytype. Slaty cleavage apparently develops due in part to pressure solution of phyllosilicates oriented parallel to bedding, mass transport of components, and crystallization to form new grains parallel to cleavage. It reflects transitions from imperfect, metastable phases toward ordered stable phases in a low temperature $\left(\sim 225^{\circ} \mathrm{C}\right)$ metamorphic environment.
\end{abstract}

\section{INTRODUCTION}

SLATY cleavage development is generally recognized to involve several competitive processes that have been reviewed or discussed by a number of authors (e.g. Wood 1974, White \& Knipe 1978, Engelder \& Marshak 1985). Reorientation of phyllosilicates is central to these processes and is thought to be accomplished by one of three specific processes: (1) mechanical rotation, (2) syntectonic crystallization with growth of new grains and (3) pressure solution, wherein phyllosilicates passively change orientation as matrix minerals are removed (White \& Knipe 1978). Each of these processes has been shown to involve several factors. In any given slate, several processes may compete at any given time, and their relative significance may change as cleavage develops. For example, in some slates mechanical rotation is an important orienting mechanism and may be followed by crystallization or recrystallization (Knipe \& White 1977, Roy 1978, Gray 1979, Knipe 1979, 1981, White \& Johnston 1981, Van der Pluijm \& KaarsSijpesteijn 1984). In other slates phyllosilicates parallel to cleavage have been shown to have formed by syntectonic crystal growth without mechanical rotation (Etheridge \& Lee 1975, Gregg 1985, Woodland 1985).

The Martinsburg Formation of Pennsylvania and New Jersey has a strong regional slaty cleavage whose origin has been studied extensively. Most workers now believe that pressure solution and/or syntectonic crystallization

\footnotetext{
* Contribution Number 411 from the Mineralogical Laboratory
} Department of Geological Sciences. University of Michigan, U.S.A. mechanisms were most important during development of this cleavage (Behre 1933, Epstein \& Epstein 1969, Geiser 1975, Groshong 1976, Beutner 1978, Woodland 1982, Wright \& Platt 1982, Onasch 1983), rather than mechanical rotation (Maxwell 1962, Carson 1968, Alterman 1973).

An important outcrop of the Martinsburg Formation which exposes the gradual development of slaty cleavage in a mudstone over a distance of $100 \mathrm{~m}$ is present at Lehigh Gap. At this locality the slaty cleavage in the Martinsburg dies out within $60 \mathrm{~m}$ of its upper unconformable and faulted contact with the Silurian Shawangunk quartzitic conglomerate. Epstein \& Epstein (1969) proposed that the absence of slaty cleavage near the Shawangunk-Martinsburg contact was due to a pressure shadow created by the highly competent quartzitic conglomerate. Using an X-ray pole figure device, Holeywell \& Tullis (1975) found that near the contact, (001) of illite is parallel to the bedding plane but (001) of chlorite makes an angle of twenty degrees with bedding. As the mudstone transforms to slate, white mica gradually attains the slaty cleavage orientation, while chlorite attains the cleavage orientation about $30 \mathrm{~m}$ further from the contact. Holeywell \& Tullis (1975) and later Wintsch (1978), Lewis (1980) and Woodland (1982) all agreed that mechanical rotation cannot account for the fabrics observed, and that some crystallization process must have been involved.

At the outcrop, the Martinsburg Formation is a uniformly fine-grained argillaceous mudstone/slate, with grain-size which is generally too small to permit detailed studies of the mineralogy, chemistry and texture of individual grains. Because definition of these 


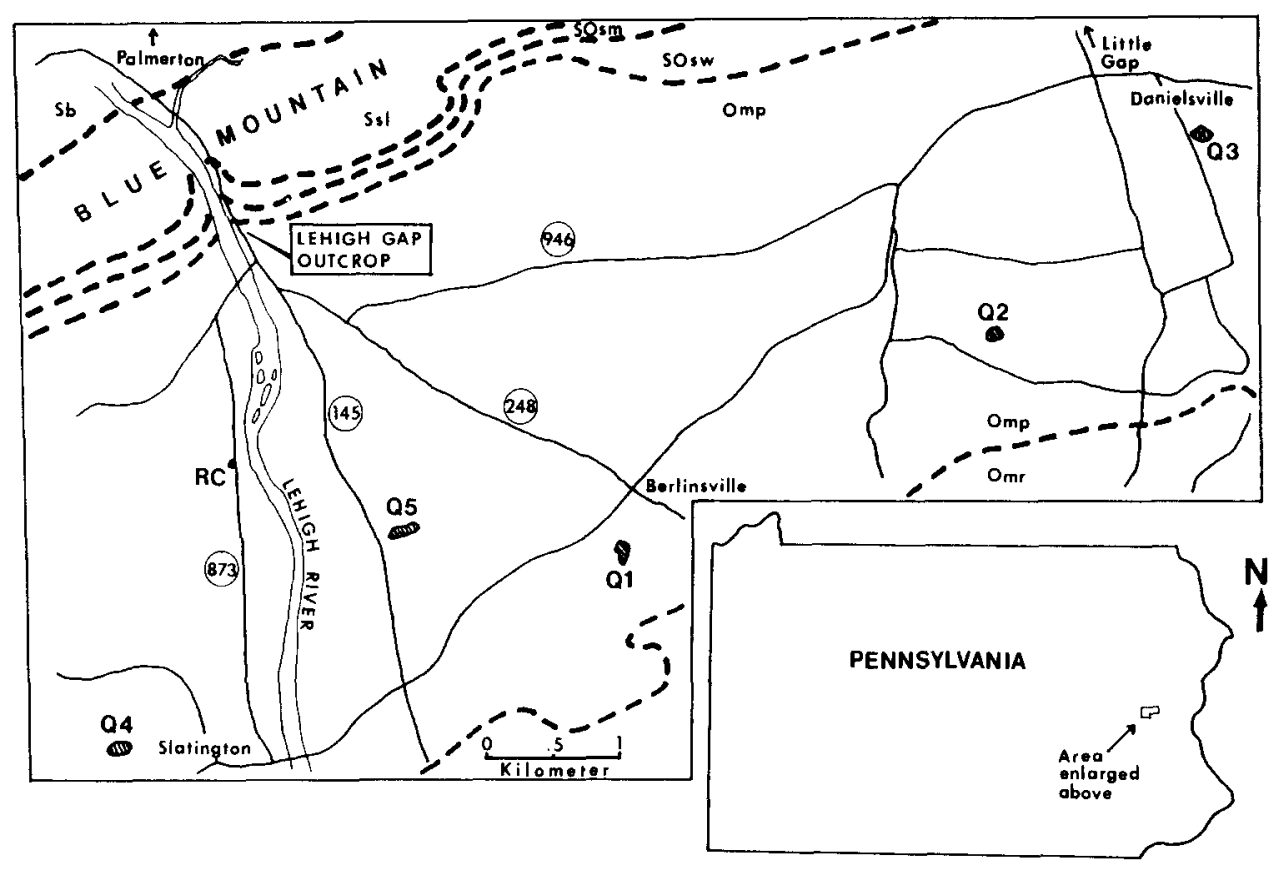

Fig. 1. Map of the sample locations in the Martinsburg Formation in the Lehigh Gap area. The geology is from Epstein et al. (1974). Stratigraphic units are: Sb, Bloomsburg Red Beds; Ssl, Lizard Creek Member, Shawangunk Formation; SOsm, Minsi Member, Shawangunk Formation; SOsw, Weiders Member, Shawangunk Formation; Omp, Pen Argyl Member, Martinsburg Formation; Omr, Ramseyburg Member, Martinsburg Formation. Q1-Q5, and RC indicate locations of slate quarries and the road cut. Roads are numbered.

parameters is essential to understanding the process(es) of development of the slaty cleavage, we have reexamined this shale to slate transition primarily utilizing the techniques of transmission electron microscopy (TEM) and analytical electron microscopy (AEM). Several aspects of this work have been separately described elsewhere (Lee \& Peacor 1983, in press, Lee et al. 1982a,b, 1983, in press, 1984), with emphasis on mineralogical features. In this paper we emphasize those parts of our observations which are related directly to slaty cleavage development.

Because we show below that cleavage developed syntectonically, with mineral reactions consistent with an increase in metamorphic grade, it is important to specify the limiting $P-T$ conditions. There are no accurate temperature indicators for metamorphism/cleavage development although a maximum temperature of approximately $200^{\circ} \mathrm{C}$ is implied using conodont coloration as a thermal indicator (Epstein 1974) and using chlorite and illite polytype transitions (Lewis 1980). Estimated temperatures from vitrinite reflectance measurements in northeastern Pennsylvania correspond to approximately $250^{\circ} \mathrm{C}$ at Lehigh Gap (Hower 1978). The sediment thickness above the Martinsburg Formation at Lehigh Gap at the time of the Alleghenian orogeny is estimated as approximately $7.5 \mathrm{~km}$ (or $P=2 \mathrm{~kb}$ ) (from the data in Colton 1970). Assuming an average geothermal gradient of $30 \pm 10^{\circ} \mathrm{C} \mathrm{km}^{-1}$ (Moses 1961), the temperature at the Shawangunk-Martinsburg contact is calculated as $225 \pm 75^{\circ} \mathrm{C}$. The occurrence of kaolinite plus quartz in these rocks (see below) places an upper limit on the temperature for the Martinsburg Formation at Lehigh Gap at approximately $300^{\circ} \mathrm{C}$ (Delany \& Helgeson 1978, Perkins et al., 1979). Although these individual estimates are all imprecise, they collectively suggest that slaty cleavage developed under $P-T$ conditions of $2 \mathrm{~kb}$ and $225 \pm 25^{\circ} \mathrm{C}$.

\section{EXPERIMENTAL METHODS}

For this study 37 samples were collected: 18 unoriented and nine oriented hand samples from 18 equally spaced locations at the Lehigh Gap outcrop, and an additional six unoriented and four oriented samples from five slate quarries (Q1-Q5 in Fig. 1) and a roadcut (RC) to the south of Lehigh Gap. These samples were first examined using optical, powder X-ray diffraction and electron microprobe analysis techniques. Seven oriented samples (four from the Lehigh Gap outcrop, three from quarries and roadcut) were then chosen for TEM/AEM investigation. Oriented polished thin sections were made so that the planes of bedding and slaty cleavage were both perpendicular to the section. After optical examination, samples for TEM and AEM observations were prepared following the procedure described by Blake et al. (1982). These procedures enabled us to orient specimens with $c^{*}$ of a high proportion of the phyllosilicates normal to the beam of the electron microscope, so as to permit observation of 001 fringe images.

A JEOL JEM-100CX scanning transmission electron microscope was used in this study. The instrument was fitted with a solid-state detector for energy dispersive $\mathrm{X}$-ray analysis and has been extensively modified in order to produce an "ultra-clean X-ray spectrum" for accurate and high resolution analysis (Blake et al. 1980, Allard \& Blake 1982). Specific TEM/AEM procedures 
have been described in detail (Lee \& Peacor 1983, in press, Lee et al. 1984, in press) and therefore are not repeated here. However, it is important to note that during analysis of illite, $\mathrm{K}$ diffuses away from the area of analysis causing values for $\mathrm{K}$ to be too low (Knipe 1979, Craw 1981). This is a serious problem, especially for small grains and, therefore, a careful calibration was undertaken in order to obtain accurate analyses.

Thin edges of the sample were observed by TEM using bright-field lattice-fringe imaging techniques in order to obtain selected area electron-diffraction patterns. Areas that showed 001 reflections were further studied by AEM by switching to STEM mode immediately following TEM observations. TEM images were obtained in a wide range of magnification for a variety of purposes; e.g. low magnifications $\left(5-33 \times 10^{3}\right.$ power) were preferentially used to study textural relationships of mineral grains whereas higher magnifications (50$250 \times 10^{3}$ power) were preferred for lattice fringe imaging in order to examine detailed micro-scale structures such as structural defects and interlayering. Much lower magnifications $\left(0.1-5 \times 10^{3}\right.$ power $)$ were often used simply to survey a sample as a whole and to locate grains of interest for analysis and higher resolution studies. Because some interpretations were qualitative, it is important to note that the small number of TEM photographs presented in this paper are chosen from hundreds of images from the sample and are selected to illustrate representative features.

\section{OBSERVATIONS}

\section{Optical study}

Optical microscopic studies of the Martinsburg Formation samples revealed major amounts of quartz, white mica, chlorite and albite, lesser quantities of carbonate, and minor amounts of pyrite and iron oxide. The majority of the individual matrix crystals of phyllosilicates are optically unresolvable although there are some phyllosilicate megacrysts (porphyroblasts of Woodland 1982) larger than $100 \mu \mathrm{m}$. Fine-grained phyllosilicates in mudstones near the contact appear fibrous in thin section and coalesce to form anastomosing trails with (001) subparallel to the bedding. The megacrysts (larger than $20 \mu \mathrm{m}$ in length or $200 \mu \mathrm{m}^{2}$ in area) consist of white mica, chlorite and intergrown chlorite-white mica. They are also oriented parallel to or at a low angle to the bedding plane.

Thin, subparallel anastomosing mica films separated by quartz and albite are poorly developed approximately perpendicular to the bedding of samples approximately $60 \mathrm{~m}$ from the contact where the incipient slaty cleavage can be observed in outcrop. This texture is well developed in the slate $130 \mathrm{~m}$ from the contact. The mica films in these samples appear to consist of individual thin subparallel units (less than $1 \mu \mathrm{m}$ thick) and their aspect ratio (length/thickness) is greater than 10 . The aspect ratio of the chlorite megacrysts decreases with the tran- sition from mudstone to slate and becomes less than one in quarry samples (Woodland 1982, Lewis 1980). The mica films from samples at the end of the outcrop where the rock has slaty cleavage are thicker (lower in aspect ratio), more continuous and appear to truncate the edges of the phyllosilicate grains which are parallel to bedding. Similar features were observed by Holeywell and Tullis (1975). However, macroscopic slaty cleavage is still non-pervasive because thick domains without phyllosilicates separate the mica films which are parallel to the slaty cleavage. Pressure shadows are observed on the sides of the megacrysts perpendicular to (001) layers where fine-grained white mica, chlorite, quartz and iron oxide occur. Orientations of the trace of (001) of chlorite megacrysts show that most grains remain parallel to or at a low angle to the bedding plane even in slates (Lewis 1980). In all samples, but especially in those in the incipient stages of cleavage development, the optically resolvable megacrysts show virtually no internal deformation or mechanical reorientation toward the cleavage plane; only a very few grains in the most highly deformed quarry samples show evidence for kinking into the cleavage orientation.

The above textures have been well illustrated by Holeywell \& Tullis (1975) and Woodland (1982) in optical micrographs and are therefore not pictured here. Reference to them verifies that the textural features (with the exception of the megacrysts) in the pelites occur on the scale of less than $50 \mu \mathrm{m}$; i.e. the individual grains are a few $\mu \mathrm{m}$ or less in diameter, and films of phyllosilicates are separated by less than approximately $40 \mu \mathrm{m}$. So that the TEM studies are shown to sample the relevant textures, we note that all TEM specimens were obtained from well-characterized thin sections. Only then were $3 \mathrm{~mm}$ diameter specimens selected and thinned, so that the areas studied were up to $0.5 \mathrm{~mm}$ in diameter and thus much larger than the scale of heterogeneity.

\section{$X$-ray diffraction data}

Semi-quantitative modal analyses of the major constituent minerals were performed using integrated intensities from powder X-ray diffraction patterns, as compared with data for standard curves. This resulted in the following very approximate weight per cents: illite, 35; quartz, 45; chlorite, 10; plagioclase, 10 . The intensity ratios of selected peaks for each mineral and standard $\mathrm{Al}_{2} \mathrm{O}_{3}$ were plotted against sample locations (distance from the Shawangunk-Martinsburg contact) (Fig. 2); the results indicate no significant changes in proportions of these four minerals across the mudstone-slate transition.

Crystallinity of illite was estimated as proposed by Weaver (1960) using the peak height ratio at $10 \AA$ to that at $10.5 \AA$ (i.e. sharpness ratio). However, it does not correlate well with the mudstone to slate transition (Fig. 3). Although the broadest and least symmetric peaks are found for samples in the mudstone, those samples with the best developed slaty cleavage in the 


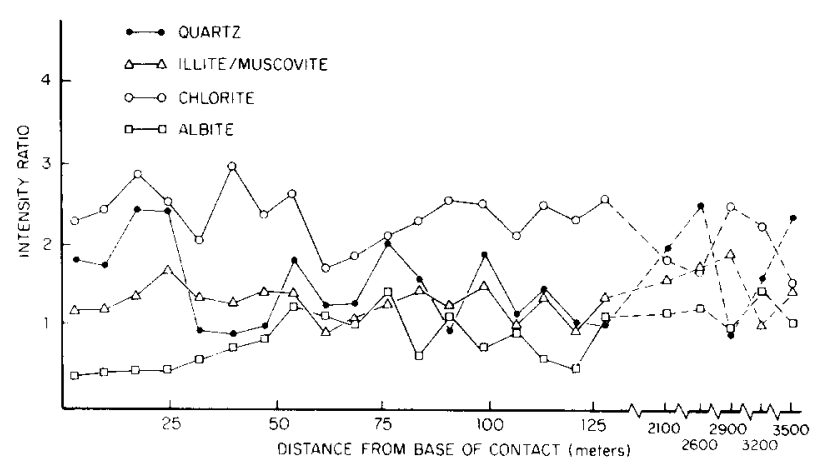

Fig. 2. Intensity (peak height) ratios of quartz (100), chlorite (002), white mica $(002)$, and albite $(002)$ reflections to the (116) peak of the internal standard (synthetic corundum). Intensity ratios are plotted as a function of the distance from the Shawangunk-Martinsburg contact. Quarry samples; Q1, $2100 \mathrm{~m}$; Q2, $2600 \mathrm{~m}$; Q3, $2900 \mathrm{~m}$; Q4. $3200 \mathrm{~m}$; $\mathrm{Q} 5,3500 \mathrm{~m}$ from the contact.

Lehigh Gap outcrop do not have the most symmetric $\mathrm{X}$-ray reflections.

Polytypes of dioctahedral micas were identified using the criteria of Yoder \& Eugster (1955). Samples of mudstone near the contact with the Shawangunk Formation appear to contain both $1 \mathrm{M}$ and $2 \mathrm{M}$ polytypes. However, only the $2 \mathrm{M}$ polytype was detected in samples from a slate quarry. Maxwell \& Hower (1967) showed that an increase in the ratio of the intensity of the $2.80 \AA$ peak to that of the $2.58 \AA$ peak is correlatable with an increase in the proportion of the $2 \mathrm{M}$ polytype relative to $1 \mathrm{M}_{\mathrm{d}}$. Figure 4 is a plot of this variable vs distance from the Shawangunk-Martinsburg contact. It shows a small but continuous increase in the ratio concomitant with slaty cleavage development. As shown below, the change has been verified through direct determination of polytypes by TEM.

\section{Whole rock chemical analysis}

Bulk chemical compositions were determined by $\mathrm{X}$ ray fluorescence analysis for samples across the Lehigh Gap outcrop (Table 1). All elements except $\mathrm{Na}$ remain relatively constant in concentration across the outcrop, although some local enrichment of $\mathrm{Ca}$ and $\mathrm{P}$ and possibly $\mathrm{Si}$ are implied, probably due to the presence of calcite

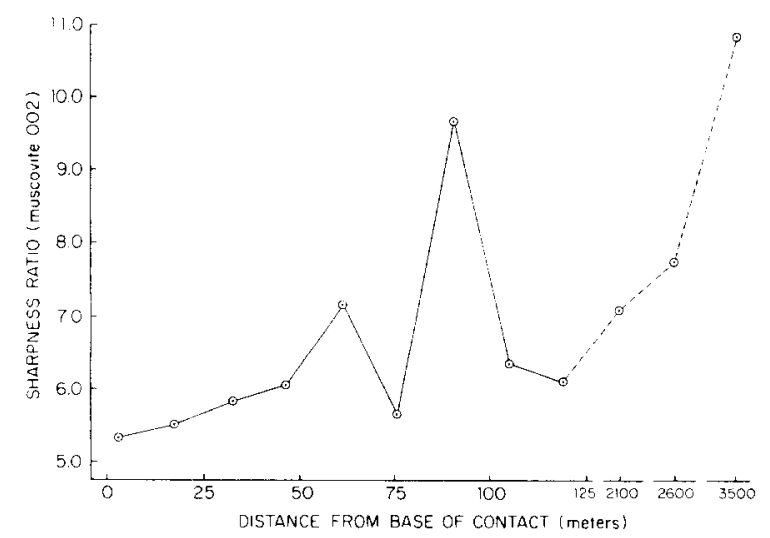

Fig. 3. Sharpness ratio of $(002)$ diffraction peak of white mica as a function of distance along outcrop.

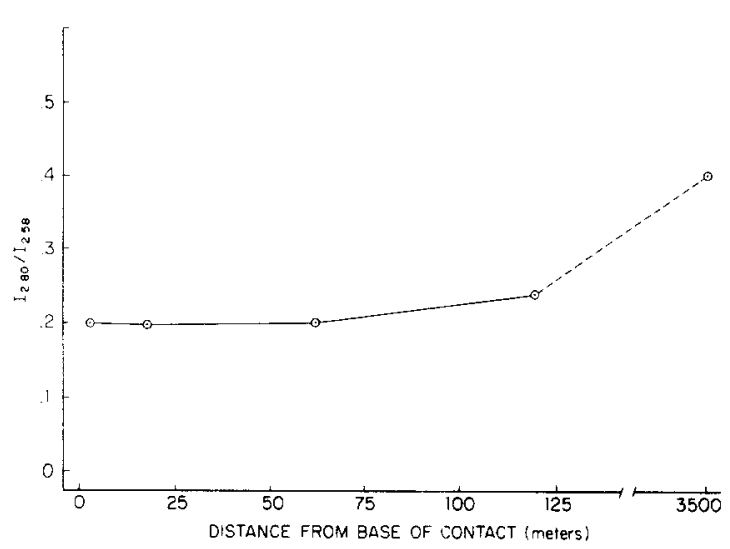

Fig. 4. Ratio of the intensity of the $2.80 \AA$ peak to that of the $2.58 \AA$ peak for illite.

and/or quartz veins or apatite. The data imply, however, that there are no significant variations in element concentrations concomitant with the mudstone to slate transition. Mineralogical transitions that occur across the outcrop therefore cannot be due to changes in bulk composition of the rocks.

\section{Electron microscopy}

Orientation. Orientation of $c^{*}$ for illite and chlorite were measured using (001) reflections from selectedarea electron diffraction patterns. Data for several hundred illite and chlorite grains in mica films from four oriented samples (one or two TEM specimens for each sample) are plotted in Fig. 5. This method only gives orientation of a grain unweighted by diffraction intensity (volume of grain) and therefore must be interpreted with caution.

These data show that basal planes of illite and chlorite are dominantly parallel to the bedding plane of mudstone near the contact (Fig. 5a). However, there is a significant proportion of grains in other orientations. Parallelism of phyllosilicates to the bedding is sharply reduced in the next sample (Fig. 5b) which is further from the contact. It has a near uniform distribution of orientations, but with a suggestion of a preferred orientation parallel to slaty cleavage for the illite fraction. The proportion of illite and chlorite grains that are parallel to slaty cleavage increases from Fig. 5(b) to Fig. 5(d); the last corresponds to the slate in the Lehigh Gap outcrop. In all samples, there is a substantial proportion of grains in other orientations.

These data confirm that there is indeed an increase in the proportion of grains oriented parallel to cleavage as detected at the TEM scale, but without the occurrence of an intermediate orientation in the transitional samples. Caution must be exercised in interpretation of the data, however, as the number of samples is small and the areas observed by TEM are limited in extent. However, assuming that the four samples represent stages in a continuous process as seen in outcrop (and verified by XRD, etc.) and that the limited areas studied by TEM 
Table 1. X-ray fluorescence analysis of whole rock samples, Martinsburg Formation at Lehigh Gap. Values expressed as weight per cent

\begin{tabular}{|c|c|c|c|c|c|c|c|c|}
\hline & $1 \mathrm{~m}^{*}$ & $\begin{array}{c}8 \mathrm{~m} \\
(\mathrm{LG} 4)\end{array}$ & $\begin{array}{c}30 \mathrm{~m} \\
(\mathrm{LG} 10)\end{array}$ & $55 \mathrm{~m}$ & $100 \mathrm{~m}$ & $\begin{array}{c}110 \mathrm{~m} \\
(\mathrm{LG} 17)\end{array}$ & $\begin{array}{c}130 \mathrm{~m} \\
(\mathrm{LG} 20)\end{array}$ & $\begin{array}{l}3200 \mathrm{~m} \\
(\mathrm{Q} 4) \dagger\end{array}$ \\
\hline $\mathrm{SiO}_{2}$ & 62.0 & 58.4 & 59.4 & 55.2 & 59.1 & 57.3 & 62.6 & 56.1 \\
\hline $\mathrm{TiO}_{2}$ & 1.21 & 1.03 & 1.04 & 0.85 & 1.14 & 1.06 & 0.94 & 0.76 \\
\hline $\mathrm{Al}_{2} \mathrm{O}_{3}$ & 15.2 & 17.2 & 16.2 & 16.8 & 17.6 & 15.3 & 14.9 & 15.3 \\
\hline $\mathrm{Fe}_{2} \mathrm{O}_{3} \ddagger$ & 8.58 & 8.81 & 7.80 & 7.88 & 8.29 & 6.86 & 6.52 & 6.59 \\
\hline $\mathrm{MgO}$ & 2.52 & 2.48 & 2.82 & 2.72 & 2.94 & 2.49 & 2.66 & 3.00 \\
\hline $\mathrm{CaO}$ & 0.11 & 0.07 & 1.09 & 0.18 & 0.04 & 0.26 & 0.07 & 4.96 \\
\hline $\mathrm{MnO}$ & 0.03 & 0.02 & 0.09 & 0.13 & 0.04 & 0.03 & 0.03 & 0.06 \\
\hline $\mathrm{Na}_{2} \mathrm{O}$ & 0.44 & 0.37 & 0.76 & 0.53 & 0.47 & 0.93 & 0.71 & 1.34 \\
\hline $\mathrm{K}_{2} \mathrm{O}$ & 3.98 & 4.43 & 4.02 & 4.37 & 4.53 & 3.79 & 3.53 & 3.40 \\
\hline $\mathrm{P}_{2} \mathrm{O}_{5}$ & 0.23 & 0.16 & 0.82 & 0.19 & 0.13 & 0.15 & 0.12 & 0.14 \\
\hline $\mathrm{Rb}$ & 0.017 & 0.016 & 0.016 & 0.017 & 0.019 & 0.016 & 0.015 & 0.014 \\
\hline $\mathrm{Sr}$ & 0.021 & $<0.010$ & 0.009 & 0.001 & $<0.001$ & 0.002 & $<0.001$ & 0.020 \\
\hline $\mathrm{Zr}$ & 0.032 & 0.020 & 0.019 & 0.014 & 0.019 & 0.020 & 0.014 & 0.017 \\
\hline LOI\& & 5.00 & 6.23 & 4.77 & 10.5 & 4.93 & 10.5 & 6.77 & 6.70 \\
\hline Total & 99.4 & 99.3 & 98.9 & 99.4 & 99.3 & 98.7 & 98.9 & 98.4 \\
\hline
\end{tabular}

${ }^{*}$ Distance in meters from the Shawangunk-Martinsburg contact.

$\uparrow$ Sample from a slate quarry.

$\ddagger$ Total iron as $\mathrm{Fe}_{2} \mathrm{O}_{3}$.

$\S \mathrm{LOI}=$ lost on ignition.

Analyses performed by X-ray Assay Laboratory, Ontario, Canada.

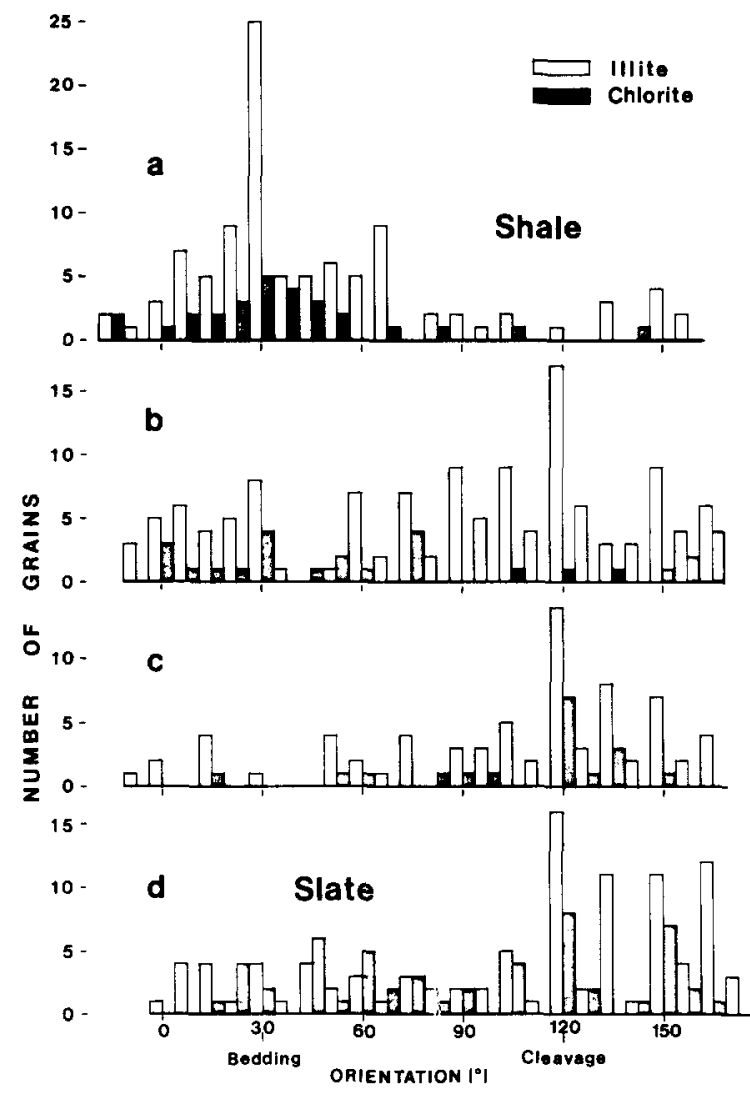

Fig. 5. Histograms showing changes in orientation of phyllosilicates for the mudstone to slate transition in the Lehigh Gap outcrop. Numbers of grains are plotted against the direction of $c^{*}$ of illite (white) and chlorite (shaded). (a) Samples are from mudstone; (b) and (c) both from intermediate samples, but at different locations, (c) being farther than (b) from the mudstone; (d) samples are from the slate of the outcrop. The angles on the horizontal scale are arbitrary. are representative of the samples (see above) the data indicate that the change from bedding to cleavage orientation is apparently discontinuous; i.e. there is not a progressive change from the bedding orientation to the cleavage orientation. This is consistent with the results of Holeywell \& Tullis (1975). Their results were for a more complete set of samples and were determined for much larger volumes of a single sample. Nevertheless, the combined results imply that the samples studied by TEM were representative of the changes in phyllosilicates that occur with the development of slaty cleavage.

Figures 6(a)-(d) illustrate phyllosilicate grains in various orientations including those which are parallel to bedding and cleavage and which are mutually perpendicular. Phyllosilicates, dominantly illite, are in general parallel to the bedding in mudstone. In many cases, however, they also display a fan-like arrangement, deviating from the bedding direction by up to $20-30$ degrees as in Fig. 6(a).

In samples transitional to slate (Figs. $6 \mathrm{~b} \& \mathrm{c}$ ) and in slates (Fig. 6d), phyllosilicate grains often occur in two different directions which are mutually perpendicular, one being parallel to the bedding and the other parallel to the cleavage. In such cases, layers in the bedding orientation abruptly terminate at the layers parallel to the cleavage orientation. In general, layers of the latter are not transected by the former. Holeywell \& Tullis (1975) made similar observations at the optical scale.

The textures shown in Figs. 6(a)-(d) are representative of many hundreds of observations. Because they were obtained from samples for which the orientation data (Fig. 6) were obtained, we assume that the grains oriented parallel to bedding and parallel to cleavage are representative of the reactants and products, respec- 
tively. This is, of course, not necessarily the case for any specific image. However, we show in the following sections that those grains identified as being parallel to bedding have many other features that differentiate them from grains parallel to cleavage; this further implies that the grains imaged as being parallel to cleavage owe their occurrence to the transition from shale to slate.

Figures 6(a)-(d) also illustrate our observation that virtually all the lattice fringes of phyllosilicates are straight; that is, there is an absence of internal deformation or other evidence of mechanical strain. Only in the single example shown in Fig. 6(c) are some layers of illite in bedding-parallel orientation slightly bent at the contact with cross-cutting layers in the cleavage orientation.

Degree of crystal perfection. Four principal classes of imperfections are found in phyllosilicates of mudstones and they are representative of the transition process in burial diagenesis and low temperature metamorphism, as observed in Gulf Coast sediments and rocks from the Lehigh Gap outcrop (Lee et al. in press). The four classes are: (1) curved, anastomosing (001) structure layers as seen in mixed-layer illite/smectite-the layers often show variable interlayer spacing, indicative of heterogeneity within individual layers; (2) individual layer terminations resembling classical edge dislocations; (3) low-angle grain boundary-like features where packets of layers intersect at small angles and layer terminations (dislocations) are concentrated along the boundaries and (4) disorder in layer stacking sequences, as random mixed-layering of more than one structure type in chlorite-illite interlayering, and as intermixing of polytypes of a single structure type. All imperfections except type 1 are commonly observed in samples from the Lehigh Gap outcrop.

The imperfections observed in the Lehigh Gap samples show characteristic trends with development of cleavage. Typical textures are illustrated in Figs. 7 and 8 for mudstone and slate, respectively. The edge dislocations (layer terminations) (Fig. 7b) are found in all of the samples, but in general less frequently in slate samples than in mudstone samples. Packets of phyllosilicate layers in mudstone samples are characterized in part as being separated from one another by low-angle grain boundary-like features (e.g. Fig. 7b). In slate samples, those grain boundaries intersecting at small angles are almost parallel and semicoherent along (001) structure layers. Although quantitative measurements cannot be made, concentrations of defects appear to be uniform within samples, and the proportions exhibited by the mudstone samples (Figs. 7a \& b) are much greater than those of the slate samples (Figs. 8a \& b). Figure 7(b) illustrates concentrations of layer terminations along low-angle grain boundary-like features. Even in a grain which appears to be a single crystal, layer boundaries are largely incoherent with concentrations of layer terminations and dislocations along several linear features (Fig. 7b). In slate samples (Fig. 8a \& b), however, there are far fewer imperfections. Low-angle grain boundaries become coherent or semicoherent and layers across them are parallel or subparallel to each other. Stacking disorder by interlayering of different crystal structures is generally absent.

Chlorite-illite interlayering. The changes in chloriteillite interlayering consequent to the mudstone to slate transition are discussed and illustrated in detail by Lee $e t$ al. (1984) and are therefore only briefly summarized here. In the mudstone, chlorite is commonly found randomly interlayered within packets of illite. Such mixed-layering occurs most frequently in samples in the intermediate range of the mudstone to slate transition. Randomly intermixed chlorite-illite layers are commonly observed and, in some cases, portions of grains even contain $1: 1$ ordered chlorite-illite mixed-layering (Lee \& Peacor, in press). A third type of layer (7 $\AA$-chlorite) occurs only randomly interlayered with chlorite $(14 \AA)$ and illite. Intralayer transitions between these three structure types sometimes occur as described by Lee \& Peacor (1983). Interlayering of chlorite and illite at an individual layer level is not found in slates. In the slate samples from quarries, well defined, homogeneous chlorite or illite/muscovite layers interleave as packets with average thickness of up to a few thousand Ångströms.

Kaolinite-illite interlayering. Kaolinite is observed in all samples studied from the Lehigh Gap outcrop, although it is scarce relative to illite or chlorite and not detectable by X-ray diffraction. Kaolinite is characterized by discrete (001) layers of $7 \AA$ periodicity (Figs $9 \mathrm{a} \& \mathrm{~b}$ ). Data from qualitative AEM analyses show high $\mathrm{Al}$ and $\mathrm{Si}$ and low $\mathrm{Fe}$ and $\mathrm{Mg}$. Some $\mathrm{K}$ appeared in the spectra as a result of contamination by adjacent illite, because packets of kaolinite layers are generally very thin (only a few hundreds of Angstroms thick) and always occur interleaved with illite or muscovite (Figs. 9a \& b). Kaolinite has not been observed as separate grains or interleaved with trioctahedral phyllosilicates. The boundaries between kaolinite and illite or muscovite are semicoherent with layers approximately parallel to each other (Figs. 9a \& b). The average thickness of kaolinite packets is approximately $200-500 \AA$ in mudstone. They sometimes appear as groups of packets alternating with packets of illite layers (Fig. 9b). The thickness and abundance of kaolinite packets, however, decrease from mudstone to slate samples of the Lehigh Gap outcrop. The average packet thickness of kaolinite in the slate is less than $100 \AA$, and no packets were observed in the quarry samples. Figures $9($ a) \& (b) show typical kaolinite packets in mudstone and slate, respectively, and illustrate the decrease in their thickness which accompanies the mudstone to slate transition. It is important to note that TEM lattice fringe images of kaolinite are difficult to obtain because of extremely rapid beam damage occurring within only one minute. Kaolinite may therefore go undetected unless the TEM operator carries out the necessary functions efficiently and rapidly. 

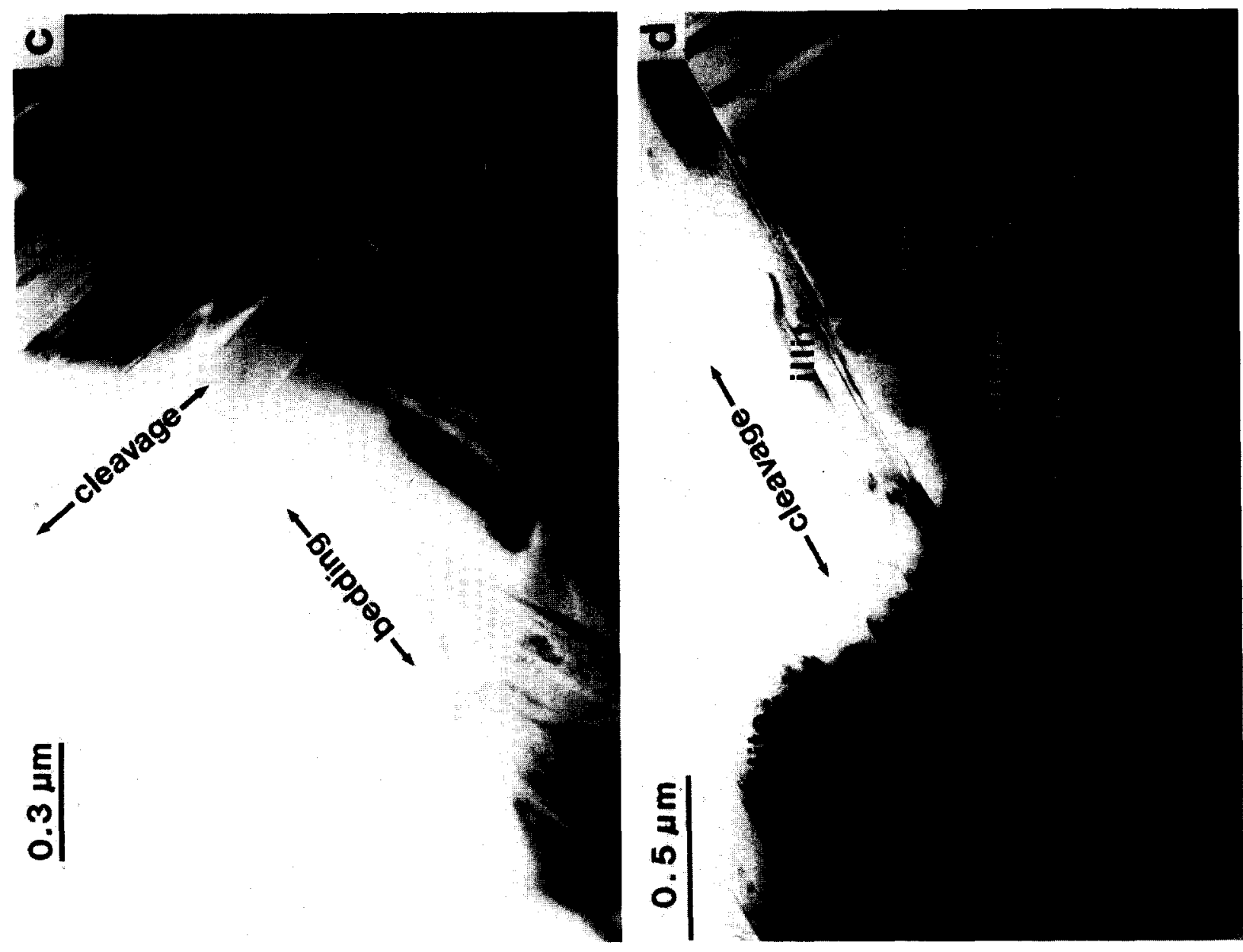

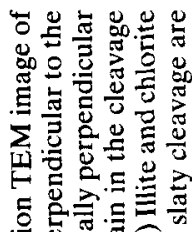

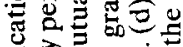

늘 절

品

ह.

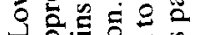

중

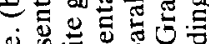

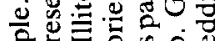

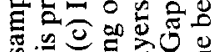

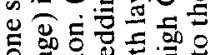

कृ

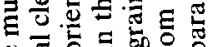

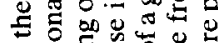

.

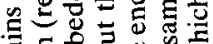

品. 웅

Q

कo 5.50

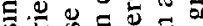

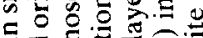
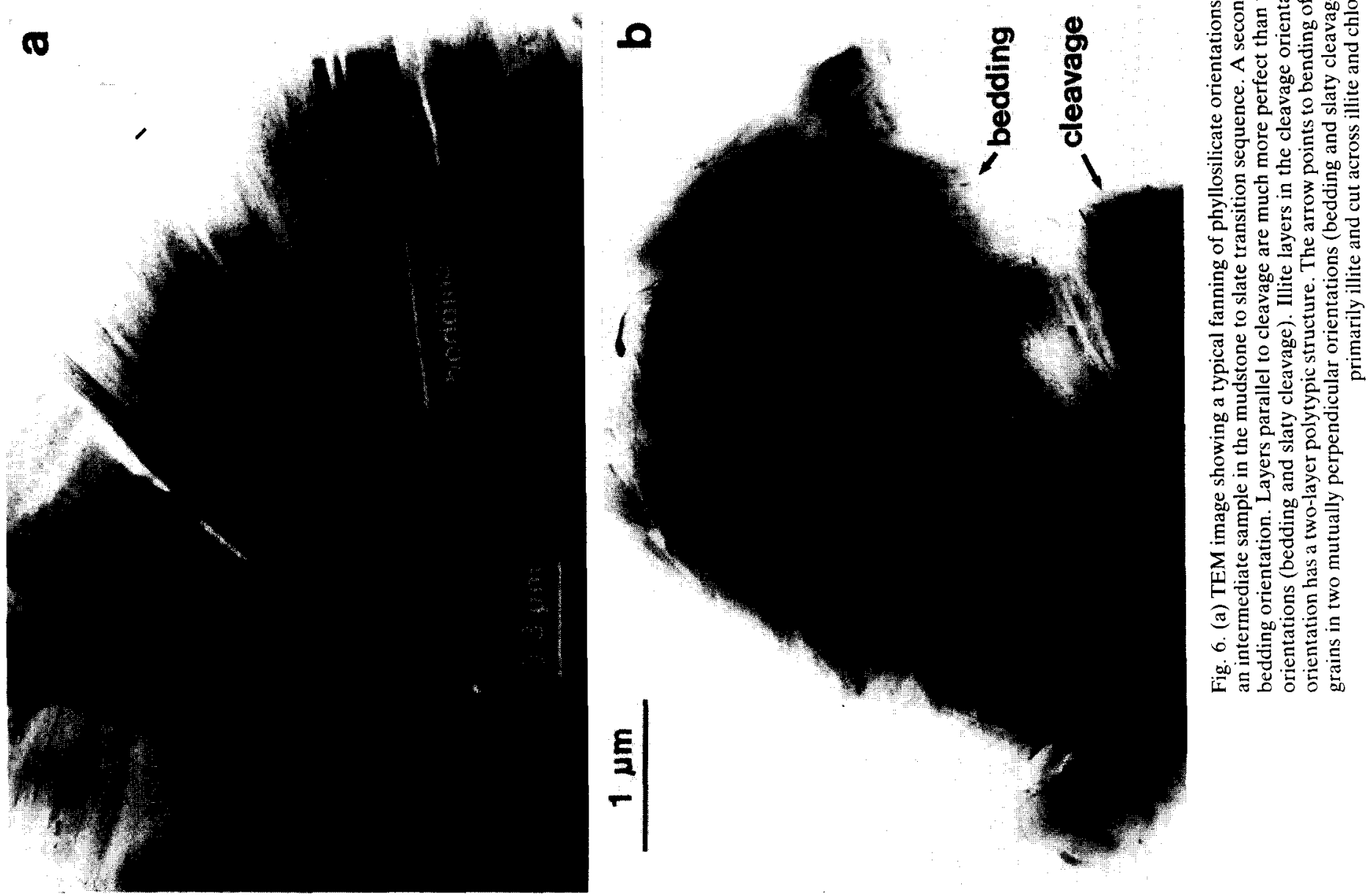


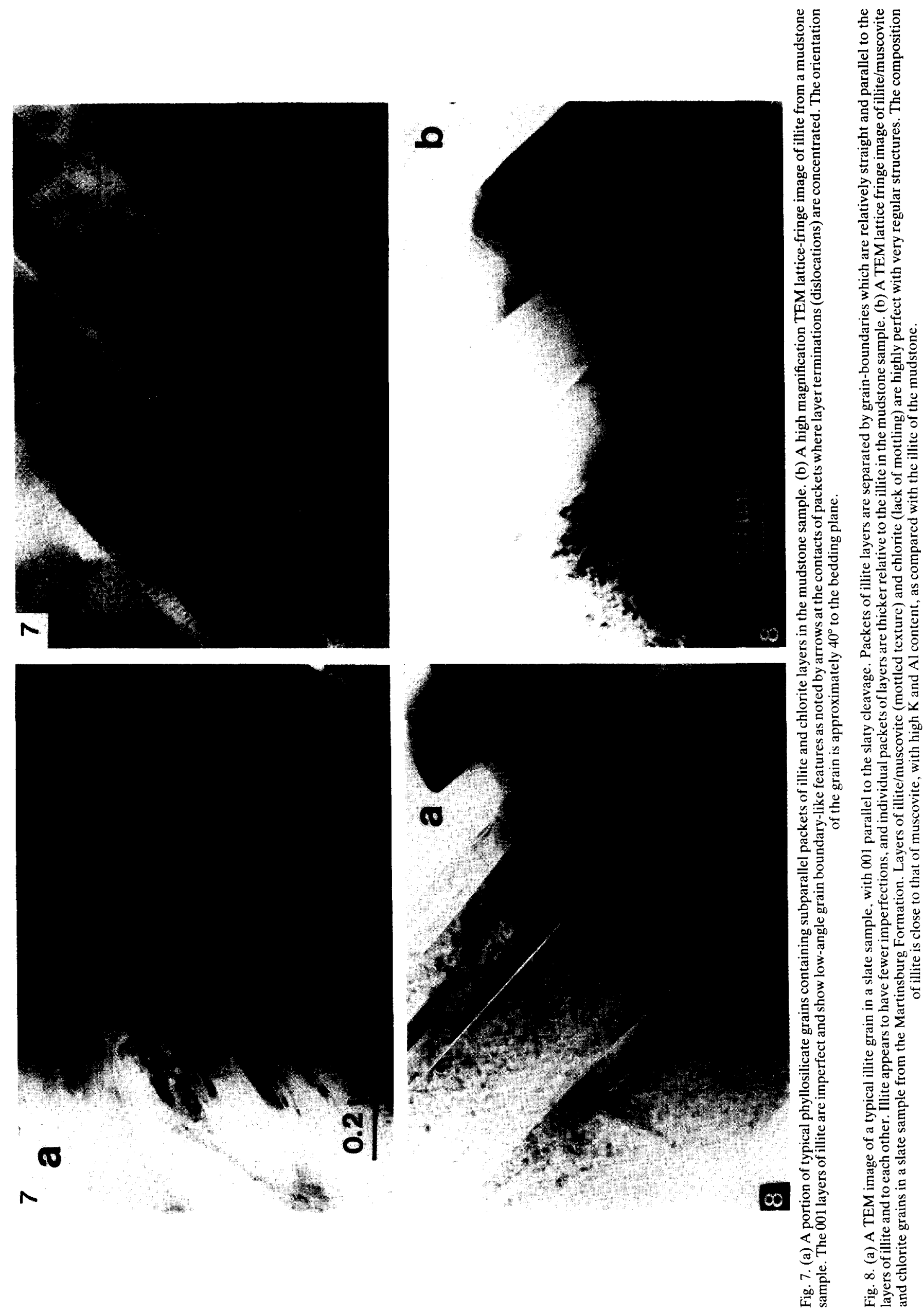


Syntectonic crystallization for the mudstone to slate transition, Pennsylvania
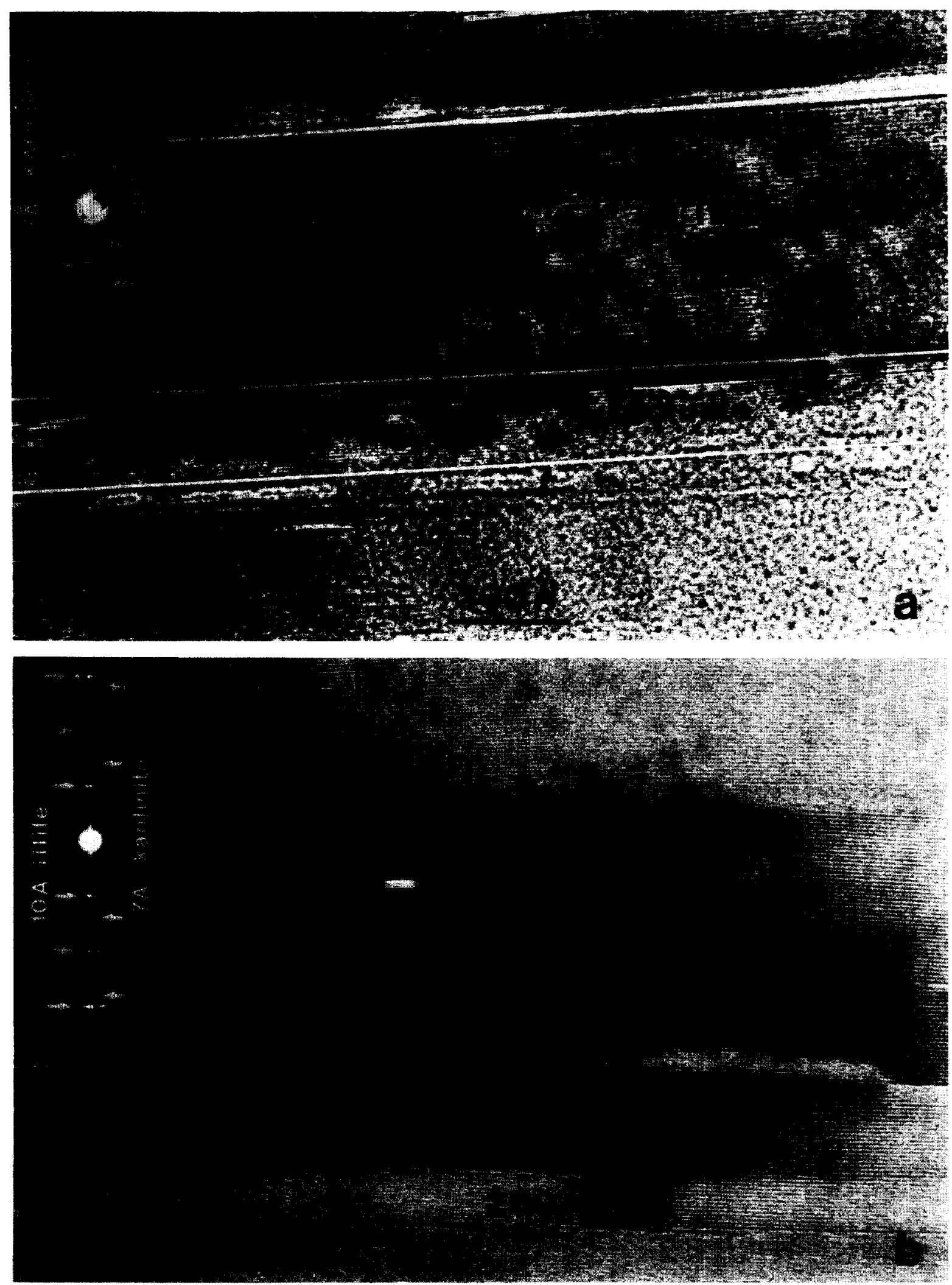

Fig. 9. (a) TEM lattice fringe images of packets of kaolinite lavers interlayered within illite grains. The sample is from the mudstone. (b) TEM lattice fringe image of interleaved kaolinite and illite layers in the slate of the Lehigh Gap outcrop. The packet thicknesses are less than those in the mudstone (a). 


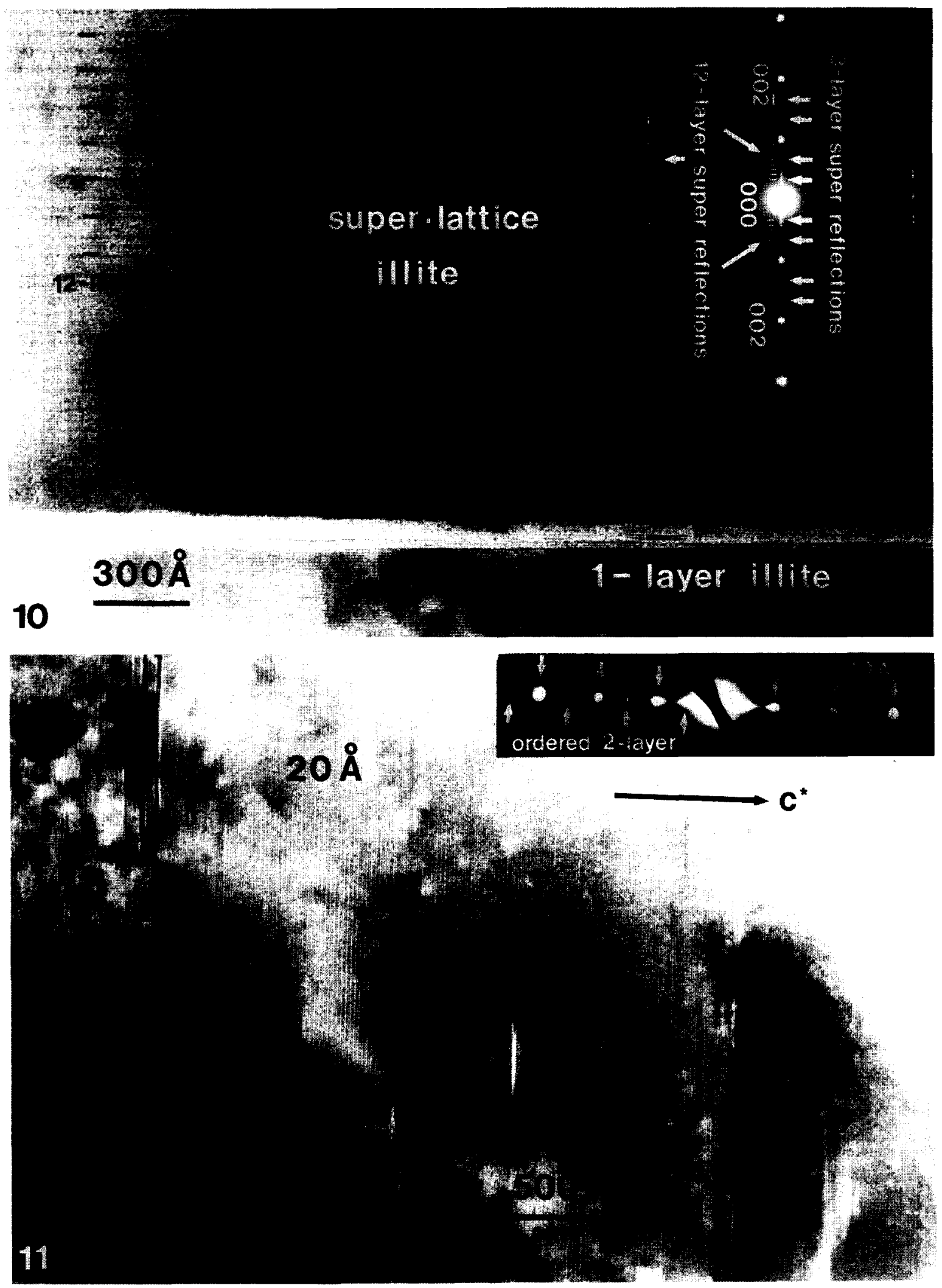

Fig. 10. TEM lattice fringe image of illite showing super-lattice periodicities. At the lower portion of the photograph are shown 001 layers of a regular 1-layer illite. The super-lattice layers show a general repeat of 12-layer units, and 3-layer superperiodicities are included within the 12-layer repeat units. The inset electron diffraction pattern for this area also shows three-layer periodicities superimposed on 12-layer units. The sample is from the mudstone of the Lehigh Gap outcrop.

Fig. 11. A TEM image of a two-layer illite/muscovite polytype in a sample from the quarry. The inset electron diffraction pattern shows regular $20 \AA$ two-layer periodicity. 
Illite polytypism. In addition to changes in orientation and crystal perfection, illite transforms toward muscovite in both polytypism and chemical composition. Twolayer polytypes of illite as well as one-layer sequences are found in samples throughout the entire sequence of the transition from mudstone to slate. However, twolayer polytypes are observed far more frequently in slate than in mudstone in which the one-layer sequence predominates. Two or more polytypes are frequently interlayered in mudstone and transitional samples, but not in slates. Some portions of such domains show a rather regular repeat of three-layer units superimposed on 12-layer units (Fig. 10). Grains of two-layer polytypes are larger in general, giving rise to sharper reflections in electron diffraction patterns with little diffuseness parallel to $c^{*}$ (Fig. 11). X-ray powder diffraction studies indicate that the two-layer polytype is of the $2 \mathrm{M}$ type. The two-layer polytypic sequence is detectable in electron diffraction patterns only for specific orientations of a grain relative to the beam. Most orientations give rise only to 001 reflections and therefore provide no data on stacking sequences. The actual proportion of two-layer illite polytypes must therefore be much higher than has been observed.

AEM data. Normalized AEM analytical data for illite from three different samples were listed in Table 3 of Lee et al. (1984). For the shale and transitional samples, data were given for illite grains with layers approximately parallel to both the bedding and cleavage directions. It was assumed that grains oriented parallel to the cleavage owed their orientation to the transition. The analytical data obtained showed systematic trends, consistent with transitions in the illite, and in concert with the textural changes described above.

All analyses of illite for all three samples show significant amounts of $\mathrm{Mg}$ and $\mathrm{Fe}$. However, we were unable to detect any systematic changes in the proportions of these elements concomitant with the shale to slate transition, in contrast to the observations of Knipe (1981) who observed for other slates an increase in $\mathrm{Mg}$ and $\mathrm{Fe}$ in grains crystallizing with orientations parallel to cleavage.

The principal changes in composition of the illite include large increases in $\mathrm{K}$ and $\mathrm{Al}$ in the illite of the slate (oriented parallel to cleavage) relative to illite in the mudstone (oriented parallel to bedding). Illite differs from muscovite largely in having up to half of the interlayer sites vacant, with charge balance maintained through higher proportions of Si relative to tetrahedrally coordinated Al. Such illite, produced largely through diagenesis, transforms toward muscovite with the substitutions $\mathrm{K}+\mathrm{Al}$ for [ ] + Si. The low contents of $\mathrm{K}$ and $\mathrm{Al}$ in illite in the mudstone reflect the expected values for illite in a diagenetic burial metamorphic environment. Even the illite of the mudstone oriented parallel to the cleavage has a similar composition, implying that such grains have an orientation randomly determined by diagenetic factors, unrelated to slaty cleavage.

By contrast, the average $\mathrm{K}$ and $\mathrm{Al}$ contents of grains parallel to the cleavage in the transitional sample are significantly greater than the contents of these elements in grains parallel to bedding in the same samples, and approach those for the slate. This supports, but does not prove, the relation that the higher proportion of grains parallel to cleavage in the transitional sample have attained their orientation as a change from the original texture of the mudstone, concomitant with the development of cleavage. The analyses of illite parallel to cleavage in the slate further support this relation. The compositions of the highly ordered crystals in the slate approach those of a stoichiometric, phengitic mica.

\section{DISCUSSION}

The above data place important constraints on the process and driving forces for slaty cleavage development at Lehigh Gap. The results fall into two general categories: textural and mineralogical, and are discussed in that order.

Textural relationships. In spite of the optical and SEM studies of samples from Lehigh Gap (Epstein \& Epstein 1969, Holeywell \& Tullis 1975, Woodland 1982, this study) and of other samples of the Martinsburg Formation (Groshong 1976, Beutner 1978, Woodland 1982, Onasch 1983), very little evidence for internal deformation or rigid-body rotation of phyllosilicate grains has been found. The same is true here of TEM observations. Thousands of TEM images, obtained from low power to the scale of lattice fringe images, produced only a single example of apparent bending of layers of a phyllosilicate. In those samples which are transitional from mudstone to slate, phyllosilicates with layers approximately parallel to bedding commonly have those layers terminated against straight layers of grains oriented approximately parallel to cleavage. The opposite relation is not observed.

The most critical observation here is that even on the TEM scale a preferred orientation intermediate between those of bedding and cleavage is absent in transitional samples. Mechanical rotation of individual grains requires that each grain pass through intermediate orientations (e.g. Knipe 1981, Etheridge \& Lee 1985). The absence of intermediate orientations at Lehigh Gap might indicate that the cleavage development process has gone to completion, but this is contrary to the low strain in the mudstone (Holeywell \& Tullis 1975, Wintsch 1978) and the common orientation of phyllosilicates parallel to bedding. Thus the textural relationships observed on the scale of TEM support the conclusions of most other workers, that mechanical rotation of phyllosilicates was not a significant process in slaty cleavage development at Lehigh Gap.

Mineralogical relationships. The above results show that there is a strong correlation between mineralogy and position in the transition zone. The white micas in the bedding orientation are dominantly the $1 \mathrm{M}$ poly- 
type, have a higher density of imperfections, and are on average more aluminous (phyllosilicatic). Interlayering of $10 \AA$ dioctahedral mica with chlorite or kaolinite is common in the mudstones, as is the occurrence of mixed layering between $10 \AA$ mica and chlorite. In contrast, the white mica in the slates is dominated by the $2 \mathrm{M}$ polytype, has a low density of imperfections, and is less aluminous. The degree of interlayering with kaolinite is much reduced and interlayering between chlorite and illite on an individual layer level is absent. These data provide compelling evidence that mechanical rotation could not have been a significant process in the formation of slaty cleavage, because rotation would not have modified the grains in any way. Whatever the mechanism, a reconstructive process must have been involved to accomplish so thorough a transformation of the white mica in the slates.

Orienting mechanism. The mechanism by which the slaty cleavage developed is an important question. A pressure solution mechanism has been proposed by most authors, but in the strict sense is not consistent with our results. Preferred orientation by this mechanism is established by the rotation of phyllosilicates as "insoluble residue", and does not necessarily require the reconstitution of this "residue" (e.g. White \& Knipe 1978). Syntectonic crystallization, however, is completely consistent with our results. In this case the reconstitution of diagenetic phyllosilicates has apparently taken place in part across sharp high-angle grain boundaries. In spite of the complete lack of evidence for any significant porosity, even at the TEM scale, there is no reason to believe that fluid was not present during the development of this cleavage, presumably as a grain boundary film or in part associated with dislocations as implied by the results of Yau et al. (1984) and Veblen \& Buseck (1980). The mineralogical and textural relations imply that the diagenetic phyllosilicates dissolved into this fluid, probably aided by relatively high normal stresses (i.e. by pressure solution). New phyllosilicate grains with different compositions and structures subsequently precipitated out of this aqueous fluid in the new orientation of the slaty cleavage.

Role of fluids. It is possible that a fluid was not pervasive on the scale of this outcrop, or even on the scale of a thin section. Pressure solution might be expected to have caused not only the dissolution but also the removal of the components in quartz and albite, down any stress-induced chemical potential gradients. Thus at the outcrop at Lehigh Gap, a chemical potential gradient on the scale of $100 \mu \mathrm{m}$ should have driven the diffusive mass transfer of $\mathrm{SiO}_{2}$ and possibly also $\mathrm{Na}_{2} \mathrm{O}$ and $\mathrm{Al}_{2} \mathrm{O}_{3}$ away from the rocks with the best developed slaty cleavage, and presumably toward the less strained mudstones. The bulk chemical compositions of the slates and mudstones show no important chemical variations across the outcrop (Table 1), with the possible exception of a slight increase in $\mathrm{SiO}_{2}$ and $\mathrm{Na}_{2} \mathrm{O}$ in the slates. This is consistent with the constant modal mineralogy across the outcrop. The lack of such chemical and mineralogical trends does not preclude the existence of a pervasive fluid, but may imply that fluid flow during slaty cleavage development was not important.

The compositions of the white micas and chlorites in a slate sample (Lee et al. 1984, tables 3 and 4) may also reveal something about the process of syntectonic crystallization. Different grains of both illite and chlorite in the orientation of the slaty cleavage from a single thin section show analytically significant differences in the concentrations of most elements at the scale of resolution of AEM data. This requires that either they did not precipitate from a pervasive aqueous fluid of uniform composition at the same time, or that they precipitated at the same time from a fluid which was inhomogeneous in composition on the scale of $\mathrm{mm}$. Certainly these grains could not have precipitated at exactly the same time, and certainly the local pressure solution of individual grains would be expected to have a strong instantaneous control on composition in a rock with small porosity. Thus fluid composition should probably not be considered uniform or pervasive on the scale of reaction at this outcrop ( $100 \mathrm{~m}$ and perhaps $\left.10^{5} \mathrm{a}\right)$.

Driving force. The driving force for the reaction of the diagenetic micas to the slaty cleavage micas must be a reduction in the total energy. Specific sources of energy contributing to metastability of minerals in the mudstone include crystal structure (or polytype), chemical composition, surface and interfacial area, defects and elastic strain (e.g. Reitan 1977, Green 1984, Wintsch 1985). We have found good evidence for contributions from most of these in the rocks at Lehigh Gap. The increase in order (to $2 \mathrm{M}$ polytype), and in size, the refinement to a more phengitic composition, and the decrease in defect density of the illites in the cleavage orientation relative to those in the bedding orientation indicate that each variable contributed to the metastability of the diagenetic illite. The fact that the diagenetic illites still maintain these features in the mudstones implies that these features alone did not supply the driving force for the transformation. In the absence of evidence for the internal deformation of the phyllosilicates (folding or kinking of grains) recoverable elastic strain energy is the only source left that could have provided the activation energy for the transformation; thus the transformation must have been syntectonic. However, the metastability of the phyllosilicates inherited from diagenesis may have contributed significantly to the overall driving force, thus lowering the magnitude of elastic strain energy required to activate the process.

\section{SUMMARY}

The data collectively indicate that diagenetic phyllosilicates oriented preferentially parallel to bedding have syntectonically dissolved with subsequent precipitation of more highly ordered phengitic muscovite in a preferred orientation parallel to cleavage. Changes in 
mineralogy are consistent with those expected for prograde metamorphic processes and further emphasize the relation between strain features and metamorphic reactions as discussed by many authors (e.g. Beach 1979, Knipe 1981, White \& Johnston 1981). The commonly observed termination of layers parallel to bedding against layers parallel to cleavage suggests that the dissolution/crystallization reaction may have occurred at such sites. Aqueous fluids must have been involved in this solution/precipitation process, but the constancy of bulk composition and variability of individual grain composition suggest that the composition of this fluid was not uniform in time and/or space. Elastic strain energy is implicated as providing the activation energy for the transformation, but the metastable states of phyllosilicates in the bedding orientation as reflected in microstructures, textures and chemistry could have been an important factor in the dissolution of the diagenetic grains.

Acknowledgements--We are indebted to Dr. Larry Allard, Dr. David Blake and the members of the University of Michigan Electron Microbeam Analysis Laboratory for their invaluable help. We are especially grateful to Professors Eric Essene, Bruce Wilkinson, Ben Van der Pluijm and David Wiltschko of the Department of Geological Sciences of the University of Michigan for their valuable discussions and comments. This manuscript was greatly improved by the contributions of two anonymous reviewers. Mr. Jung Ho Ahn, Ms. Lancy Yau, Ms. Susan Penoyar and Ms. Margaret Allard of the Department of Geological Sciences are also thanked for their help and fruitful discussions. The study was supported in part by NSF grant EAR-8107529 to Donald R. Peacor.

\section{REFERENCES}

Allard, L. F. \& Blake, D. F. 1982. The practice of modifying an analytical electron microscope to produce clean X-ray spectra. Microbeam Analysis-1982 (edited by Heinrich, K. F. J.). San Francisco Press, San Francisco, 8-19.

Alterman, I. B. 1973. Rotation and dewatering during slaty cleavage formation: some new evidence and interpretations. Geology 1, 33-36.

Beach, A. 1979. Pressure solution as a metamorphic process in deformed terrigenous sedimentary rocks. Lithos 12, 51-58.

Behre, C. H. 1933. Slate in Pennsylvania. Penn. Geol. Survey, 4th ser., Mineral. Resource Rept. 16, 1-400.

Beutner, E. C. 1978. Slaty cleavage and related strain in Martinsburg slate, Delaware Water Gap, New Jersey. Am. J. Sci. 278, 1-23.

Blake, D. F., Allard, L. F., Peacor, D. R. \& Bigelow, W. C. 1980. "Ultra-clean" X-ray spectra in the JEOL JEM-100CX. Proc. 38th meeting Electron Microscope Study of America, 136-137.

Blake, D. F., Peacor, D. R. \& Wilkinson, B. H. 1982. The sequence and mechanism of low-temperature dolomite formation: calcian dolomites in a Pennsylvanian echinoderm. J. sedim. Petrol. 52 , 59-70.

Carson, W. P. 1968. Development of flow cleavage in the Martinsburg Shale, Port Jervis South area (northern New Jersey). Tectonophysics 5, 531-541.

Colton, G. W. 1970. The Appalachian basin-its depositional sequences and their geologic relationships. In: Studies of Appalachian Geology-Central and Southern (edited by Fisher, G. W., Pettijohn, F. J., Reed, J. C. Jr. \& Weaver, K. N.). Wiley, New York, 5-47.

Craw, D. 1981. Oxidation and microprobe-induced potassium mobility in iron-bearing phyllosilicates from the Otago schists, New Zealand. Lithos 14, 49-57.

Delany, J. M. \& Helgeson, H. C. 1978. Calculation of the thermodynamic consequences of dehydration in subducting oceanic crust to $100 \mathrm{~kb}$ and $800^{\circ} \mathrm{C}$. Am. J. Sci. 278, 638-686.
Engelder, T. \& Marshak, S. 1985. Disjunctive cleavage formed at shallow depths in sedimentary rocks. J. Struct. Geol. 7, 327-343.

Epstein, J. B. 1974. Metamorphic origin of slaty cleavage in eastern Pennsylvania. Abs. with Prog. geol. Soc. Am. 6, 724.

Epstein, J. B. \& Epstein, A. G. 1969. Geology of the Valley and Ridge province between Delaware Water Gap and Lehigh Gap, Pennsylvania. In: Geology of Selected Areas in New Jersey and Eastern Pennsylvania and Guidebook of Excursion, New Brunswick, New Jersey (edited by Subitzky, S.). Rutgers Univ. Press, 132-205.

Epstein, J. B., Sevon, W. D. \& Glaeser, J. D. 1974. Geology and mineral resources of the Lehighton and Palmerton quadrangles, Carbon and Northampton Counties, Pennsylvania. Penn. Geol. Survey, 4th ser. Atlas $195 \mathrm{ed}$.

Etheridge, M. A. \& Lee, M. F. 1975. Microstructure of slates from Lady Loretta, Queensland, Australia. Bull. geol. Soc. Am. 86, 13-22.

Geiser, P. A. 1975. Slaty cleavage and the dewatering hypothesis-an examination of some critical evidence. Geology 3, 717-720.

Gray, D. R. 1979. Microstructure of crenulation cleavages: an indicator of cleavage origin. Am. J. Sci. 279, 97-128.

Green, H. W. 1984. "Pressure solution" creep: some causes and mechanisms. J. geophys. Res. 89, 4313-4318.

Gregg, W. J. 1985. Microscopic deformation mechanisms associated with mica film formation in psammitic rocks. J. Struct. Geol. 7, $45-56$

Groshong, R. H., Jr. 1976. Strain and pressure solution in the Martinsburg slate, Delaware Water Gap, New Jersey. Am. J. Sci. 276, 1131-1146.

Holeywell, R. C. \& Tullis, T. E. 1975. Mineral reorientation and slaty cleavage in the Martinsburg Formation, Lehigh Gap, Pennsylvania. Bull. geol. Soc. Am. 86, 1296-1304.

Hower, J. C. 1978. Anisotropy of vitrinite reflectance in relation to coal metamorphism for selected U.S. coals. Unpublished Ph.D. thesis, Pennsylvania State University.

Knipe, R. J. 1979. Chemical changes during slaty cleavage development. Bull. Mineral. 102, 206-209.

Knipe, R. J. 1981. The interaction of deformation and metamorphism in slates. Tectonophysics $\mathbf{7 8}, 249-272$.

Knipe, R. J. \& White, S. H. 1977. Microstructural variation of an axial plane cleavage around a fold-a HVEM study. Tectonophysics $\mathbf{3 9}$, $355-380$.

Lee, J. H., Peacor, D. R. \& Wintsch, R. P. 1982a. TEM and AEM study of changes in dioctahedral micas during slaty cleavage development. EOS, Trans. Am. geophys. Un. 63, 468.

Lee, J. H., Peacor, D. R. \& Wintsch, R. P. 1982b. TEM and AEM study of interlayering and along-layer transitions in tri- and dioctahedral phyllosilicates. Abs. with Prog. geol. Soc. Am. 14, 544.

Lee, J. H. \& Peacor, D. R. 1983. Interlayer transitions in phyllosilicates of the Martinsburg shale. Nature, Lond. 303, 608-609.

Lee, J. H. \& Peacor, D. R., in press. Ordered 1: 1 interstratification of chlorite and illite: a Transmission and Analytical electron microscopic study. Clays Clay Miner.

Lee, J. H., Peacor, D. R., Lewis, D. D. \& Wintsch, R. P. 1983. Evidence for a solution-recrystallization origin of slaty cleavage at Lehigh Gap, Pennsylvania. EOS, Trans. Am. geophys. Un. 64, 319.

Lee, J. H., Ahn, J. H. \& Peacor, D. R., in press. Textures in layered silicates: Progressive changes through diagenesis and low temperature metamorphism. J. sedim. Petrol.

Lee, J. H., Peacor, D. R., Lewis, D. D. \& Wintsch, R. P. 1984 Chlorite-illite/muscovite interlayered and interstratified crystals: a TEM/AEM study. Contr. Miner. Petrol. 88, 372-385.

Lewis, D. D. 1980. An investigation of the preferred orientation of phyllosilicates in the Martinsburg slate, Lehigh Gap area, Pennsylvania. Unpublished MA thesis, Indiana University, Bloomington, Indiana.

Maxwell, J. C. 1962. Origin of slaty cleavage and fracture cleavage in the Delaware Water Gap area, New Jersey and Pennsylvania. In: Petrologic Studies (edited by Engel, A. E. J., James, H. L. \& Leonard, B. F.), Geol. Soc. Am. Buddington V., 281-311.

Maxwell, D. T. \& Hower, J. 1967. High-grade diagenesis and lowgrade metamorphism of illite in the Precambrian Belt Series. Am Mineral. 62, 843-857.

Moses, P. L. 1961. Geothermal Gradients. World Oil 152, 79-82.

Perkins, D., III, Essene, E. J., Westrum, E. F., Jr. \& Wall, V. J. 1979. New thermodynamic data for diaspore and their application to the system $\mathrm{Al}_{2} \mathrm{O}_{3}-\mathrm{SiO}_{2}-\mathrm{H}_{2}$ O. Am. Mineral. 64, 1080-1090.

Onasch, C. M. 1983. Dynamic analysis of rough cleavage in the Martinsburg Formation, Maryland. J. Struct. Geol. 5, 73-82.

Reitan. P. M. 1977. Energetics of metamorphic reactions. Lithos 10, 121-128. 
Roy, A. B. 1978. Evolution of slaty cleavage in relation to diagenesis and metamorphism: a study from the Hunsrückschiefer. Bull. geol. Soc. Am. 89, 1775-1785.

Van der Pluijm, B. A. \& Kaars-Sijpesteijn, C. H. 1984. Chlorite-mica aggregates: morphology, orientation, development and bearing on cleavage formation in very low-grade rocks. J. Struct. Geol. 6, $339-407$.

Veblen, D. R. \& Buseck, P. R. 1980. Microstructures and reaction mechanisms in biopyriboles. Am. Mineral. 65, 599-623.

Weaver, C. E. 1960. Possible uses of clay minerals in the search for oil. Clays Clay Miner. 8, 214-227.

White, S. H. \& Johnston, D. C. 1981. A microstructural and microchemical study of cleavage lamellae in a slate. J. Struct. Geol. 3, 279-290.

White, S. H. \& Knipe, R. J. 1978. Microstructure and cleavage development in selected slates. Contr. Miner. Petrol. 66, 165-174.

Wintsch, R. P. 1978. A chemical approach to the preferred orientation of mica. Bull. geol. Soc. Am. 89, 1715-1718.

Wintsch, R. P. 1985. The possible effects of deformation on chemical processes in metamorphic fault zones. In: Metamorphic Reactions.
Kinetics, Textures and Deformation (edited by Thompson, A. B. \& Rubie, D. C.), Springer, New York, 251-267.

Wood, D. S. 1974. Current views on the development of slaty cleavage. A. Rev. Earth Planet. Sci. 2, 369-401.

Woodland, B. G. 1982. Gradational development of domainal slaty cleavage, its origin and relation to chlorite porphyroblasts in the Martinsburg Formation, eastern Pennsylvania. Tectonophysics 82, 89-124.

Woodland, B. G. 1985. Relationship of concretions and chloritemuscovite porphyroblasts to the development of domainal cleavage in low grade metamorphic deformed rocks from north-central Wales, Great Britain. J. Struct. Geol. 7, 205-215.

Wright, T. O. \& Platt, L. B. 1982. Pressure dissolution and cleavage in the Martinsburg Shale. Am. J. Sci. 282, 122-135.

Yau, Y., Anovitz, L. M., Essene, E. J. \& Peacor, D. R. 1984. Phlogopite-chlorite reaction mechanisms and physical conditions during retrograde reactions in the Marble Formation, Franklin, New Jersey. Contr. Miner. Petrol. 88, 299-306.

Yoder, H. S. \& Eugster, H. P. 1955. Synthetic and natural muscovites. Geochim. cosmochim. Acta. 8, 225-280. 